\title{
Lutibaculum baratangense gen. nov., sp. nov., a novel proteobacterium isolated from a mud volcano, Andamans, India
}

\author{
Anil P. Kumar, T. N. R. Srinivas, S. Madhu and S. Shivaji \\ International Journal of Systematic and Evolutionary Microbiology doi: 10.1099/ijs.0.027094-0. \\ Published online ahead of print on 10 December 2010
}

The authors would like to retract this publication in order to improve the chemotaxonomic data as it has become apparent that there are inconsistencies in the data presented in this paper. This paper has been retracted from IJSEM Papers in Press and will not be published in print in IJSEM.

\section{Stappia aquimarina sp. nov., isolated from seawater}

\author{
Wen-Ming Chen, Fu-Sian Sheu, A. B. Arun, Chiu-Chung Young \\ and Shih-Yi Sheu \\ International Journal of Systematic and Evolutionary Microbiology doi: 10.1099/ijs.0.030643-0. \\ Published online ahead of print on 18 March 2011
}

Due to miscommunication and confusion over the designation of this novel isolate, two papers describing this strain were submitted independently by different members of the groups who collaborated in this research. As a result, this paper has been retracted at the request of all of the authors and the other paper has been withdrawn. A new manuscript that combines the data obtained by both teams is now in preparation with the agreement of all parties. 